\title{
NEW INVERSE DEA MODELS FOR BUDGETING AND PLANNING
}

\author{
TAhere SAYAR ${ }^{1}$, Mojtaba GhiYasi ${ }^{2, *}$ AND JAFAR FAthali ${ }^{1}$
}

\begin{abstract}
Data envelopment analysis (DEA) measures the efficiency score of a set of homogeneous decision-making units (DMUs) based on observed input and output. Considering input-oriented, the inverse DEA models find the required input level for producing a given amount of production in the current efficiency level. This article proposes a new form of the inverse DEA model considering income (for planning) and budget (for finance and budgeting) constraints. In contrast with the classical inverse model, both input and output levels are variable in proposed models to meet income (or budget) constraints. Proposed models help decision-makers (DMs) to find the required value of each input and each output's income share to meet the income or budget constraint. We apply the proposed model in the efficiency analysis of 58 supermarkets belonging to the same chain. However, these methods are general and can be used in the budgeting and planning process of any production system, including business sectors and firms that provide services.
\end{abstract}

Mathematics Subject Classification. 90C05, 90C08, 90C29.

Received October 31, 2020. Accepted April 20, 2021.

\section{INTRODUCTION}

Data Envelopment Analysis (DEA) is a linear programming technique-based for evaluating the relative efficiency of a decision-making unit (DMU) by comparing it with other DMUs that first time as proposed by Charnes et al. [4], known as the CCR model. This technique has been used and developed by many scholars, see, e.g., $[6,15]$. In recent years, Wei et al. [25] proposed the inverse DEA models that aim to answer this question: if among a group of DMUs, we increase certain inputs to a particular unit and assume that the DMU maintains its current efficiency level with respect to other units, how much more outputs could the unit produce? If the outputs need to be increased to a certain level and the unit's efficiency remains unchanged, how much more inputs should be provided to the unit? These types of questions are answered using Multiple Objectives Linear Programming (MOLP) in general in the inverse DEA literature. Different researchers introduce some extensions and modifications. After the initial work in inverse DEA by Wei et al. [25], it has been remarkably considered by some scholars in the DEA field see e.g., $[8,11,13,16-20,23,24,26]$. Along the lines of Wei et al. [25] the inverse problem was investigated in inverse DEA filed by Hadi-Vencheh et al. [14]. They used (weak) Pareto solutions of MOLP problems to estimate the desired inputs Both Questions input-estimation and output-estimation are investigated under the inter-temporal dependence assumption by Jahanshahloo et al. [20]. They are proposed a new optimality

Keywords. DEA, inverse DEA, MOLP, budget constraint, income constraint.

1 Faculty of Mathematical Sciences, Shahrood University of Technology, Shahrood, Iran.

2 Faculty of Industrial Engineering and Management Sciences, Shahrood University of Technology, Shahrood, Iran.

*Corresponding author: mgt.ghiasi@gmail.com 
notion for multiple objective programming problems periodic weak Pareto optimality [19] dealt with inverse DEA problem with non-radial input-output change. Gattoufi et al. [8] proposed an application of the inverse DEA models in merger and acquisition in banking. They developed an approach to realize the required level of the merged bank's inputs and outputs to reach a predetermined efficiency target. Amin and Emrouznejad [2] applied the inverse optimization for forecasting and provided a streamlined approach to time series analysis using inverse linear programming. Amin et al. [3] proposed inverse DEA models for modeling generalized firms' restructuring and anticipating the minor and major consolidation for a merger in a market. Ghiyasi [9] dealt with cost and revenue efficiency in the inverse DEA context. Emrouznejad et al. [7], Ghiyasi [10] dealt with the inverse DEA models in the presence of undesirable outputs. Kalantary and Saen [22] proposed an inverse dynamic network DEA model for assessing the sustainability of supply chains. In another research, Kalantary et al. [21] proposed an inverse version of network dynamic range adjusted measure for sustainability assessment of supply chains. Chen et al. [5] investigated the investment problem of sustainable development in China utilizing an inverse DEA model that is capable of dealing with undesirable outputs. Ghiyasi [9] proposed an inverse DEA based method for emission utilization permission while taking the environmental efficiencies into consideration. Emrouznejad et al. [7] proposed an inverse DEA model for allocation of $\mathrm{CO}_{2}$ emission for different chines regions. Guijarro et al. [12] dealt with technical inverse DEA and the merge problem that their model computes the global efficiency target by giving preference to merging DMUs over saving inputs. Zhang and Cui [27] dealt with the inverse DEA based on non-redial DEA that call non-redial inverse DEA. Amin and Boamah [1] dealt with inverse data envelopment analysis (DEA) and cost efficiency model for estimating potential gains from mergers and restructuring scenarios for firms that want to minimize cost. The price information is important and valuable information in economic theory and in real-world applications. Taking the price information in hand, we can measure the revenue and cost and, consequently, the production system's profit. Thus, cost and revenue also play an essential role in real-world applications. Specifically, cost measure, some believe that the economics' art is managing the cost and revenue of a production system since available resources, including a budget, are usually limited.

The current article proposes a new class of inverse DEA to the literature. It considers the budget constraint in the inverse DEA models and instead of increasing inputs and seeking for producible output with the same measure of efficiency. This paper considers a specific and limited budget that can be spent for buying different inputs (material vs. service or equipment vs. manpower), and the aim is estimating producible output with current efficiency measures. In contrast with classical inverse DEA models, we do not have any predetermined input or output level. Both input and output are decision variables in our model. The second model is planningbased and considers the total income, and sets a total income goal. It estimates the required value of each input and income share of each output to reach the goal. The rest of the paper is organized as follows. Section 2 provides preliminarily of DEA and inverse DEA models. Section 3 proposes two new classes of inverse DEA models that consider income and budget constraints. Section 4 applies proposed models for efficiency analysis of 58 supermarkets belonging to the same chain in Tehran city, Iran's capital.

\section{Preliminarily}

\subsection{Classical DEA models}

Suppose there are n DMUs as $\left(\mathrm{DMU}_{1}, \ldots, \mathrm{DMU}_{n}\right)$ in which $\mathrm{DMU}_{j}(j=1, \ldots, n)$, produces multiple positive outputs $y_{r j}(r=1, \ldots, s)$, by utilizing multiple positive inputs $x_{i j}(i=1, \ldots, m)$. Let input and output vector for $\mathrm{DMU}_{j}$ be denoted by $X_{j}=\left(x_{j 1}, \ldots, x_{j m}\right)$ and $Y_{j}=\left(y_{j 1}, \ldots, y_{j s}\right)$ previously.

To discuss the inverse DEA problem, we use the generalized DEA models, which is defined as follows: (Suppose unit under assessment is $\mathrm{DMU}_{o}(o \in\{1, \ldots, n\})$. Consider the following general model in terms of returns to scale for estimating the efficiency of $\mathrm{DMU}_{o}$. 


$$
\begin{aligned}
& \theta_{o}=\min \theta \\
& \text { s.t. } \sum_{j=1}^{n} \lambda_{j} x_{i j} \leq \theta x_{i 0} \quad i=1, \ldots, m \\
& \sum_{j=1}^{n} \lambda_{j} y_{r j} \geq y_{r 0} \quad r=1, \ldots, s \\
& \lambda \in \Omega
\end{aligned}
$$

where

$$
\Omega=\left\{\lambda \mid \lambda=\left(\lambda_{1}, \ldots, \lambda_{n}\right), \sigma_{1}\left(\sum_{j=1}^{n} \lambda_{j}=1+\sigma_{2}(-1)^{\sigma_{3}} v\right)=\sigma_{1}, v \geq 0, \lambda_{j} \geq 0, j=1, \ldots, n\right\} .
$$

In the above model $\sigma_{1}, \sigma_{2}$ and $\sigma_{3}$ are parameters with $0-1$ values. $\theta_{o}$ is called the input-oriented efficiency score of $\mathrm{DMU}_{0}$ and $\theta_{0} \leq 1$.

The output-oriented model for estimating the efficiency of $\mathrm{DMU}_{0}$ can be considered as follows:

$$
\begin{aligned}
& \varphi_{o}=\max \varphi \\
& \text { s.t. } \sum_{j=1}^{n} \lambda_{j} x_{i j} \leq x_{i 0} \quad i=1, \ldots, m \\
& \sum_{j=1}^{n} \lambda_{j} y_{r j} \geq \varphi y_{r 0} \quad r=1, \ldots, s \\
& \lambda \in \Omega
\end{aligned}
$$

$\varphi_{o}$ is called the output-oriented efficiency score of $\mathrm{DMU}_{0}$ and it is a well-known fact that $\varphi_{o} \geq 1$.

\subsection{Classical inverse DEA}

Now assume we perturb the output level of $\mathrm{DMU}_{o}$ from $y_{o}$ to $y_{o}+\overline{\Delta y_{o}}$. The classical inverse DEA models find the level of the required inputs needed for producing a new level of output with the current efficiency level. The following model does this aim:

$$
\begin{array}{lc}
\min \left(\Delta x_{10}, \Delta x_{20}, \ldots, \Delta x_{m 0}\right) & \\
\sum_{j=1}^{n} \lambda_{j} x_{i j} \leq \theta_{0}\left(x_{i 0}+\Delta x_{i 0}\right) & i=1, \ldots, m \\
\sum_{j=1}^{n} \lambda_{j} y_{r j} \geq\left(y_{r 0}+\Delta y_{r 0}\right) & r=1, \ldots, s \\
\lambda \in \Omega . &
\end{array}
$$

In an output orientation view, assume we perturb the inputs level of $\mathrm{DMU}_{o}$ from $x_{o}$ to $x_{o}+\overline{\Delta x_{o}}$. The classical inverse DEA model seeks for producible outputs level with the current efficiency measure as follows:

$$
\begin{array}{lr}
\max _{j=1}^{n}\left(\Delta y_{10}, \Delta y_{20}, \ldots, \Delta y_{s 0}\right) & \\
\sum_{j}^{n} \lambda_{i j} \leq\left(x_{i 0}+\Delta x_{i 0}\right) & i=1, \ldots, m \\
\sum_{j=1}^{n} \lambda_{j} y_{r j} \geq \varphi_{0}\left(y_{r 0}+\Delta y_{r 0}\right) & r=1, \ldots, s \\
\lambda \in \Omega . &
\end{array}
$$




\section{The NEW INVERSE DEA FOR BUDGETING AND PLANNING}

This section is devoted to studying a new class of inverse DEA models. The first subsection is an incomebased model with input orientation, and the second subsection is the budget-based model and has an output orientation.

\subsection{Income-based inverse DEA}

Consider the case that $\mathrm{DM}$ aims at increasing the total income of $\mathrm{DMU}_{o}$ to reach the minimum value of $A$. The question is how much input is required to get to this aim with the current efficiency level. The following model does this aim.

$$
\begin{aligned}
& \min \left(\Delta x_{10}, \Delta x_{20}, \ldots, \Delta x_{m 0}\right) \\
& \sum_{r=1}^{s} a_{r} \Delta y_{r 0} \geq A \\
& \sum_{j=1}^{n} \lambda_{j} x_{i j} \leq \theta_{0}\left(x_{i 0}+\Delta x_{i 0}\right) \\
& \sum_{j=1}^{n} \lambda_{j} y_{r j} \geq\left(y_{r 0}+\Delta y_{r 0}\right) \\
& \lambda \in \Omega,
\end{aligned}
$$

where $a_{r}, 1 \leq r \leq s$ is the price of $r$ th output. The above model finds the minimum input level for producing the desired output level and reaching the minimum total income of $\mathrm{DMU}_{o}$ to $A$ with the current efficiency level. Note that $\Delta x_{0} \in \mathbb{R}_{+}^{m}$ and $\Delta y_{0} \in \mathbb{R}_{+}^{s}$ and $\lambda \in \mathbb{R}_{+}^{n}$ are decision variables in the above model. It is important to point out that the associated classic inverse DEA model is as follows and can be considered as a special case of the model (3.1).

$$
\begin{array}{lc}
\min \left(\Delta x_{10}, \Delta x_{20}, \ldots, \Delta x_{m 0}\right) & \\
\sum_{j=1}^{n} \lambda_{j} x_{i j} \leq \theta_{0}\left(x_{i 0}+\Delta x_{i 0}\right) & i=1, \ldots, m \\
\sum_{j=1}^{n} \lambda_{j} y_{r j} \geq\left(y_{r 0}+\overline{\Delta y_{r 0}}\right) & \\
\lambda \in \Omega . &
\end{array}
$$

In the above classic inverse DEA model, an expected individual output level is considered, while MOLP (3.1) is concern about a total income level with the minimum level of inputs. In fact, $\overline{\Delta y_{r 0}}$ is the expected value of the output and therefore, it is a vector parameter in the model (3.2). Theoretical talking, both input, and output levels are variable in the model (3.1) while the output level is given and parameter in associated inverse model of (3.2). Model (3.1) has $m+s+n$ variable while its classical peer, model (3.2) has $m+n$ variable.

Remark 3.1. Classical inverse DEA model (3.2) is a special case of income-based model (3.1).

Proof. Considering $\Delta y_{r 0}=\overline{\Delta y_{r 0}}$ and ignoring the income constraint of $\sum_{r=1}^{s} a_{r} \Delta y_{r 0} \geq A$ we get the classical inverse DEA model of (3.2). The above discussion shows that the income-based model of (3.1) is generalized and more flexible than its classical peer. 
Please note that both inputs and outputs are variable in the above models, in contrast with the classic inverse DEA model. The main constraint in the model is the targeted income that should be met. It is well-known that model (3.3) is linear programming and has an optimum solution, but model (3.1) is multiple objective linear programming (MOLP) and does not have an optimal solution; instead, we have an efficient solution for this model as follows:

Definition. Suppose $\left(\lambda, x_{0}+\Delta x_{0}, y_{0}+\Delta y_{0}\right)$ is a feasible solution model (3.1), if there is no feasible solution $\left(\bar{\lambda}, x_{0}+\overline{\Delta x_{0}}, y_{0}+\overline{\Delta y_{0}}\right)$ of this model such that $x_{0}+\overline{\Delta x_{0}}, y_{0}<x_{0}+\Delta x_{0}$, then we say the $\left(\lambda, x_{0}+\Delta x_{0}, y_{0}+\Delta y_{0}\right)$ is a (weak) efficient solution of model (3.1).

Theorem 3.2. Income-based model (3.1) preserves the efficiency score of $\mathrm{DMU}_{o}$, that is, if $\left(\lambda, x_{0}+\Delta x_{0}, y_{0}+\Delta y_{0}\right)$ is a weak efficient solution of income-based model (3.1), then the efficiency of $\mathrm{DMU}_{o}=\left(x_{0}, y_{0}\right)$ and $\mathrm{DMU}_{o}^{+}=\left(x_{0}+\Delta x_{0}, y_{0}+\Delta y_{0}\right)$ are the same.

Proof. The following testing model checks the efficiency of $\mathrm{DMU}_{o}$ after perturbation.

$$
\begin{array}{ll}
\theta_{o}^{+}=\min \theta & \\
\sum_{r=1}^{s} a_{r} \overline{\Delta y_{r 0}} \geq A & \\
\sum_{j=1}^{n} \lambda_{j} x_{i j} \leq \theta\left(x_{i 0}+\overline{\Delta x_{i 0}}\right) & \\
\sum_{j=1}^{n} \lambda_{j} y_{r j} \geq\left(y_{r 0}+\overline{\Delta y_{r 0}}\right) & \\
\lambda \in \Omega . &
\end{array}
$$

If $\left(\bar{\lambda}, x_{0}+\overline{\Delta x_{0}}, y_{0}+\overline{\Delta y_{0}}\right)$ is a weak efficient solution of income based model (3.1), then it satisfies associated constraints as follows:

$$
\begin{array}{ll}
\sum_{r=1}^{s} a_{r} \overline{\Delta y_{r 0}} \geq A & \\
\sum_{j=1}^{n} \bar{\lambda}_{j} x_{i j} \leq \theta_{0}\left(x_{i 0}+\overline{\Delta x_{i 0}}\right) & \\
\sum_{j=1}^{n} \bar{\lambda}_{j} y_{r j} \geq\left(y_{r 0}+\overline{\Delta y_{r 0}}\right) & \\
\lambda \in \Omega . &
\end{array}
$$

This means $\left(\bar{\lambda}, \theta_{o}\right)$ is a feasible solution of the testing model that implies $\theta_{o}^{+} \leq \theta_{0}$. We just need to show that $\theta_{o}^{+} \ngtr \theta_{0}$. By contradiction, assume that $\theta_{o}^{+}>\theta_{0}$, which $\left(\lambda^{+}, \theta_{o}^{+}\right)$is the optimal solution of the testing model. This means that $\left(\lambda^{+}, k *\left(x_{0}+\overline{\Delta x_{0}}\right), y_{0}+\overline{\Delta y_{0}}\right)$ is a feasible solution of MOLP model (3.1) since

$$
\begin{aligned}
& \sum_{r=1}^{s} a_{r} \overline{\Delta y_{r 0}} \geq A \\
& \sum_{j=1}^{n} \lambda_{j} x_{i j} \leq \theta_{o}^{+}\left(x_{i 0}+\overline{\Delta x_{i 0}}\right)=k \theta_{0}\left(x_{i 0}+\overline{\Delta x_{i 0}}\right) \quad i=1, \ldots, m
\end{aligned}
$$




$$
\sum_{\substack{j=1 \\ \lambda \in \Omega}}^{n} \lambda_{j} y_{r j} \geq\left(y_{r 0}+\overline{\Delta y_{r 0}}\right)
$$

$$
r=1, \ldots, s
$$

where $0<k<1$. This is a contradiction with weak efficiency of $\left(\lambda, x_{0}+\Delta x_{0}, y_{0}+\Delta y_{0}\right)$. Thus, $\theta_{o}^{+} \ngtr \theta_{0}$ and therefore $\theta_{o}^{+}=\theta_{0}$.

Considering input's weight, we can use the weighted sum approach for solving the above MOLP and consequently reach the following linear programming.

$$
\begin{array}{ll}
\min & \sum_{i=1}^{m} c_{i} \Delta x_{i 0} \\
& \sum_{r=1}^{s} a_{r} \Delta y_{r 0} \geq A \\
& \\
\sum_{j=1}^{n} \lambda_{j} x_{i j} \leq \theta_{0}\left(x_{i 0}+\Delta x_{i 0}\right) & i=1, \ldots, m \\
\sum_{j=1}^{n} \lambda_{j} y_{r j} \geq\left(y_{r 0}+\Delta y_{r 0}\right) & \\
\lambda \in \Omega, &
\end{array}
$$

where $c_{i} \geq 0,1 \leq i \leq m$ is the price of $i$ th input.

Theorem 3.3. If $(\bar{\lambda}, \overline{\Delta x}, \bar{\Delta} y)$ is an optimal solution of linear programming model (3.3) then it is a weak efficient solution of MOLP model (3.1).

Proof. Since $(\bar{\lambda}, \overline{\Delta x}, \bar{\Delta} y)$ is an optimal solution of linear programming model (3.3) then it satisfies all associated constraints as follow

$$
\begin{array}{ll}
\sum_{r=1}^{s} a_{r} \overline{\Delta y_{r 0}} \geq A & \\
\sum_{j=1}^{n} \overline{\lambda_{j}} x_{i j} \leq \theta_{0}\left(x_{i 0}+\overline{\Delta x_{i 0}}\right) & i=1, \ldots, m \\
\sum_{j=1}^{n} \overline{\lambda_{j}} y_{r j} \geq\left(y_{r 0}+\overline{\Delta y_{r 0}}\right) & r=1, \ldots, s \\
\lambda \in \Omega . &
\end{array}
$$

This implies $(\bar{\lambda}, \overline{\Delta x}, \bar{\Delta} y)$ as a feasible solution of the MOLP model (3.1). By contradiction, if we assume this solution is not a weak efficient solution for the MOLP problem of (3.1) then there exists a feasible solution of this model like $(\hat{\lambda}, \widehat{\Delta x}, \widehat{\Delta y})$ such that $\widehat{\Delta x_{i 0}}<\overline{\Delta x_{i 0}}$. By multiplying both sides of this inequality by $c_{i} \geq$ $0,1 \leq i \leq m$ we get $\widehat{c_{i} \Delta x_{i 0}}<c_{i} \overline{\Delta x_{i 0}}$ and by summing up both sides of the manuscript over $1 \leq i \leq m$ we get $\sum_{i=1}^{m c_{i} \Delta} x_{i 0}<\sum_{i=1}^{m} c_{i} \overline{\Delta x_{i 0}}$ and this fact contradicts the optimality of $(\bar{\lambda}, \overline{\Delta x}, \bar{\Delta} y)$.

Remark 3.4. The optimal solution of (3.3) preserves the efficiency score of the unit under evaluation.

Proof. This can be inferred by considering Theorems 3.2 and 3.3. In fact, if $(\bar{\lambda}, \overline{\Delta x}, \bar{\Delta} y)$ is an optimal solution of linear programming model (3.3) then Theorem 3.3 implies that it is a weak efficient solution of model (3.1). 
After that, we conclude the efficiency of $\mathrm{DMU}_{o}$ are the same before and after changing its input and output levels, that is, $\mathrm{DMU}_{o}=\left(x_{0}, y_{0}\right)$ and $\mathrm{DMU}_{o}^{+}=\left(x_{0}+\Delta x_{0}, y_{0}+\Delta y_{0}\right)$.

\subsection{Budget based inverse DEA model}

In an output-oriented view, assume a given level of budget is available, and DM wants to increase its inputs. A classical case is spending a budget for improving equipment or hiring more manpower. The question is how to assign and append this budget within inputs and how much more output can be produced at the current efficiency level. The following model does this aim for us:

$$
\begin{array}{ll}
\max ^{m}\left(\Delta y_{10}, \Delta y_{20}, \ldots, \Delta y_{s 0}\right) & \\
\sum_{i=1}^{m} b_{i} \Delta x_{i 0} \leq B & \\
\sum_{j=1}^{n} \lambda_{j} x_{i j} \leq\left(x_{i 0}+\Delta x_{i 0}\right) & \\
\sum_{j=1}^{n} \lambda_{j} y_{r j} \geq \varphi_{0}\left(y_{r 0}+\Delta y_{r 0}\right) & \\
\sum_{j=1}^{n} \lambda_{j}=1 & \\
\lambda_{j} \geq 0 & j=1, \ldots, m
\end{array}
$$

where $b_{i}, 1 \leq i \leq m$ is the price of $i$ th input. In fact, the above model estimates the maximum level of output' increment of $\mathrm{DMU}_{o}$ provided with the budget constraint with the current efficiency level.

Like income based model, the classical inverse peer model of (3.4), that is, the inverse DEA model without the budget constraint, is as follows. It can be considered as a special case of a budget-based model. However, the budget-based model has $m+s+n$ variable, and its peer has only $s+n$ variable.

$$
\begin{array}{lc}
\max \left(\Delta y_{10}, \Delta y_{20}, \ldots, \Delta y_{s 0}\right) & \\
\sum_{j=1}^{n} \lambda_{j} x_{i j} \leq\left(x_{i 0}+\overline{\Delta x_{i 0}}\right) & \\
\sum_{j=1}^{n} \lambda_{j} y_{r j} \geq \varphi_{0}\left(y_{r 0}+\Delta y_{r 0}\right) & \\
\sum_{j=1}^{n} \lambda_{j}=1 & \\
\lambda_{j} \geq 0 & j=1, \ldots, m \\
&
\end{array}
$$

Both input and output levels are unknown in the budget-based model, and therefore, they are variable. Still, its peer only considers the output levels as variable, and the input levels are presumed. In other words, the budget-based model presumes only the total budget while its peer presumes all individual input levels.

In the budget-based inverse DEA model, the goal is to get the maximum possible income, thus considering the output's price. Using the weighted sum approach for solving the above MOLP, we get the following linear programming. 


$$
\begin{aligned}
& \max \sum_{r=1}^{s} a_{r} \Delta y_{r 0} \\
& \sum_{i=1}^{m} b_{i} \Delta x_{i 0} \leq B \\
& \sum_{j=1}^{n} \lambda_{j} x_{i j} \leq\left(x_{i 0}+\Delta x_{i 0}\right) \quad i=1, \ldots, m \\
& \sum_{j=1}^{n} \lambda_{j} y_{r j} \geq \varphi_{0}\left(y_{r 0}+\Delta y_{r 0}\right) \quad r=1, \ldots, s \\
& \sum_{j=1}^{n} \lambda_{j}=1 \\
& \lambda_{j} \geq 0 \\
& j=1, \ldots, n .
\end{aligned}
$$

Theorem 3.5. Budget based model (3.5) preserves the efficiency score of $\mathrm{DMU}_{o}$, that is, if $\left(\lambda, x_{0}+\Delta x_{0}, y_{0}+\Delta y_{0}\right)$ is a weak efficient solution of income-based model (2.2) and (2.3), then the efficiency of $\mathrm{DMU}_{o}=\left(x_{0}, y_{0}\right)$ and $\mathrm{DMU}_{o}^{+}=\left(x_{0}+\Delta x_{0}, y_{0}+\Delta y_{0}\right)$ are the same.

Proof. It is similar to the proof of Theorem 3.2.

Theorem 3.6. If $(\bar{\lambda}, \overline{\Delta x}, \bar{\Delta} y)$ is an optimal solution of linear programming model (3.3) then it is a weak efficient solution of MOLP model (3.1).

Proof. It is similar to the proof of Theorem 3.3.

Remark 3.7. The optimal solution of (3.3) preserves the efficiency score of the unit under evaluation.

Proof. This can be inferred by considering Theorems 3.5 and 3.6.

\section{A REAl WORLD APPlicAtion}

This section utilized our proposed approach for performance assessment, budgeting, and future planning analysis of 58 supermarkets belonging to the same chain in Tehran. Two inputs and two outputs are considered in this analysis. The size of supermarkets (in square meter) and man-hours (in hours) are considered as inputs, and sales (in Rial) and the number of loyal customers are considered as outputs. A loyal customer is considering a customer that makes a minimum level of purchase in a specific period of time. The average of labor salary and the average of one square meter supermarket's price is considered input prices used in the budget-based method. The average price of total sale and the average price of loyal customers purchased are considered as output prices. Table 1 reports the input-out data, input-oriented efficiency, and output efficiency of all supermarkets.

In the next run of analysis, we perform proposed income-based and budget-based models for going one step forward to the efficiency analysis. In the first analysis, we consider a given income level, let us say 200 million Rial that should be reached, and then perform the income-based model for all supermarkets. Table 2 reports the results of this analysis. Different supermarkets behave differently in this analysis. For instance, S3 needs no more labor but should not expect more loyal customers. S4 needs no more labor while having more loyal customers, and S10-S12 also keeps the same behavior. S23 that is an efficient supermarket need no extra inputs including size and labor but can reach more sale. S51, S57, and S58 also have the same behavior. 
TABLE 1. Input-output data and efficiency scores.

\begin{tabular}{|c|c|c|c|c|c|c|}
\hline Supermarket & $\begin{array}{l}\text { Size } \mathrm{m}^{2} \\
\left(I_{1}\right)\end{array}$ & $\begin{array}{l}\text { Man- } \\
\text { hours } \\
1^{3}\left(I_{2}\right)\end{array}$ & $\begin{array}{l}\text { Sales } \\
10^{5} R^{*}\left(O_{1}\right)\end{array}$ & $\begin{array}{l}\text { Customer } \\
\text { loyalty } \\
\left(\mathrm{O}_{2}\right) \\
\end{array}$ & $\begin{array}{l}\text { Input } \\
\text { efficiency } \\
\text { score } \theta_{j} \\
\end{array}$ & $\begin{array}{l}\text { Output } \\
\text { efficiency } \\
\text { score } \varphi_{j}\end{array}$ \\
\hline S1 & 62.75 & 2428.77 & 490.58 & 32 & 0.41 & 3.45 \\
\hline $\mathrm{S} 2$ & 59.87 & 3670.84 & 244.18 & 43 & 0.43 & 3.72 \\
\hline S3 & 81.14 & 3369.33 & 333.971 & 38 & 0.75 & 2.00 \\
\hline $\mathrm{S} 4$ & 36.05 & 1975.45 & 169.363 & 96 & 0.72 & 1.89 \\
\hline S5 & 48.3 & 2934.29 & 1010.478 & 45 & 0.54 & 2.15 \\
\hline S6 & 68.69 & 4876.08 & 813.492 & 24 & 0.40 & 2.53 \\
\hline $\mathrm{S} 7$ & 87.29 & 4443.59 & 1329.862 & 64 & 0.36 & 2.96 \\
\hline S8 & 26.86 & 2572.35 & 911.163 & 44 & 1 & 1.33 \\
\hline S9 & 54.4 & 149.71 & 1155.215 & 42 & 1 & 1 \\
\hline S10 & 44.58 & 4274.74 & 551.987 & 11 & 0.60 & 2.02 \\
\hline S11 & 41.07 & 4091.6 & 592.308 & 52 & 0.65 & 1.83 \\
\hline S12 & 38.23 & 2633.98 & 296.208 & 53 & 0.68 & 2.01 \\
\hline S13 & 51.22 & 2008 & 604.715 & 45 & 0.52 & 2.28 \\
\hline S14 & 24.49 & 1082.48 & 908.383 & 53 & 1 & 1.22 \\
\hline S15 & 30.53 & 698.22 & 1004.34 & 23 & 1 & 1 \\
\hline S16 & 42.65 & 6306.56 & 599.694 & 64 & 0.74 & 1.36 \\
\hline S17 & 43.55 & 102.6 & 149.201 & 74 & 1 & 1 \\
\hline S18 & 40.68 & 4111.14 & 289.36 & 42 & 0.60 & 3.37 \\
\hline S19 & 39.36 & 1323.11 & 1775.222 & 22 & 1 & 1 \\
\hline S20 & 78.15 & 4074.09 & 648.628 & 93 & 0.32 & 5.43 \\
\hline $\mathrm{S} 21$ & 53.79 & 4242.11 & 522.897 & 22 & 0.47 & 3.74 \\
\hline $\mathrm{S} 22$ & 39.87 & 3132.16 & 170.862 & 34 & 0.67 & 1.74 \\
\hline $\mathrm{S} 23$ & 37.35 & 1905.89 & 175.923 & 54 & 1 & 1 \\
\hline S24 & 46.7 & 2359.07 & 429.785 & 88 & 0.59 & 1.72 \\
\hline $\mathrm{S} 25$ & 49.3 & 476.3 & 630.533 & 64 & 0.67 & 2.08 \\
\hline S26 & 35.7 & 3509.22 & 218.039 & 16 & 0.77 & 1.32 \\
\hline $\mathrm{S} 27$ & 54.18 & 839.22 & 582.938 & 64 & 0.56 & 2.89 \\
\hline $\mathrm{S} 28$ & 60.21 & 2621.24 & 854.275 & 33 & 0.49 & 2.22 \\
\hline S29 & 80.26 & 3350.62 & 913.588 & 86 & 0.32 & 3.96 \\
\hline S30 & 55.97 & 2984.62 & 1408.201 & 46 & 0.65 & 1.54 \\
\hline S31 & 54.49 & 503.31 & 666.841 & 46 & 0.66 & 1.53 \\
\hline S32 & 46.6 & 6405.53 & 120.539 & 34 & 0.54 & 3.24 \\
\hline S33 & 64.19 & 5276.79 & 157.234 & 65 & 0.43 & 2.33 \\
\hline S34 & 44.93 & 2177.51 & 404.547 & 55 & 0.60 & 1.93 \\
\hline S35 & 61.14 & 3063.37 & 733.55 & 34 & 0.41 & 1.76 \\
\hline S36 & 36.44 & 1732.57 & 1058.357 & 78 & 0.91 & 1.10 \\
\hline S37 & 76.49 & 3492 & 1018.737 & 87 & 0.48 & 2.08 \\
\hline S38 & 27.63 & 641.42 & 517.371 & 65 & 1 & 1 \\
\hline S39 & 37.6 & 2206.1 & 572.871 & 34 & 0.70 & 1.77 \\
\hline $\mathrm{S} 40$ & 43.89 & 452.6 & 959.774 & 25 & 0.74 & 2.62 \\
\hline $\mathrm{S} 41$ & 53.19 & 725.34 & 1545.296 & 54 & 0.62 & 1.46 \\
\hline
\end{tabular}


TABLE 1. continued.

\begin{tabular}{lllllll}
\hline \hline Supermarket & $\begin{array}{l}\text { Size } \mathrm{m}^{2} \\
\left(I_{1}\right)\end{array}$ & $\begin{array}{l}\text { Man- } \\
\text { hours } \\
1^{3}\left(I_{2}\right)\end{array}$ & $\begin{array}{l}\text { Sales } \\
10^{5} R^{*}\left(O_{1}\right)\end{array}$ & $\begin{array}{l}\text { Customer } \\
\text { loyalty } \\
\left(O_{2}\right)\end{array}$ & $\begin{array}{l}\text { Input } \\
\text { efficiency } \\
\text { score } \theta_{j}\end{array}$ & $\begin{array}{l}\text { Output } \\
\text { efficiency } \\
\text { score } \varphi_{j}\end{array}$ \\
\hline S42 & 92.59 & 6511.8 & 575.228 & 94 & 0.47 & 1.63 \\
S43 & 71.35 & 2827.96 & 1469.73 & 44 & 0.53 & 1.93 \\
S44 & 33.89 & 3535.79 & 1670.08 & 11 & 0.72 & 1.76 \\
S45 & 83.82 & 4193.17 & 870.44 & 63 & 0.36 & 3.14 \\
S46 & 62.58 & 2478.18 & 944.269 & 33 & 0.40 & 4.48 \\
S47 & 65.26 & 1937.47 & 397.232 & 71 & 0.46 & 2.17 \\
S48 & 52.42 & 4403.41 & 480.11 & 71 & 0.57 & 1.74 \\
S49 & 32.99 & 306.03 & 685.991 & 40 & 1 & 1 \\
S50 & 53.99 & 3744.04 & 833.011 & 33 & 0.47 & 3.86 \\
S51 & 74.83 & 3343.58 & 349.108 & 93 & 0.53 & 1.90 \\
S52 & 54.04 & 4867.48 & 106.05 & 14 & 0.72 & 1.40 \\
S53 & 61.11 & 4243.02 & 1737.879 & 63 & 0.52 & 2.22 \\
S54 & 58.98 & 4066.9 & 1239.36 & 22 & 0.41 & 3.84 \\
S55 & 76.01 & 2367.89 & 691.951 & 54 & 0.35 & 3.32 \\
S56 & 94.06 & 3176.95 & 404.965 & 65 & 0.33 & 3.42 \\
S57 & 79.83 & 5292.8 & 1090.803 & 103 & 0.57 & 1.83 \\
S58 & 81.29 & 2708.43 & 232.962 & 86 & 0.45 & 2.23 \\
\hline
\end{tabular}

Notes. *Iranian Rial.

TABLE 2. Result of income based model for all supermarkets.

\begin{tabular}{lllllll}
\hline \hline Supermarket & $\Delta x_{1}$ & $\Delta x_{2}$ & $\Delta y_{1}$ & $\Delta y_{2}$ & Required Budget & Input efficiency score $\theta_{j}$ \\
\hline S1 & 65.69445 & 1888.967 & 1189.426 & 45.01186 & 87.32781 & 0.29 \\
S2 & 58.54212 & 309.6543 & 1197.794 & 37.54188 & 43.69583 & 0.27 \\
S10 & 34.49361 & 0 & 1195.545 & 3954.940 & 21.21357 & 0.49 \\
S18 & 10.08074 & 645.0443 & 1178.360 & 54.89065 & 78.02075 & 0.23 \\
S25 & 33.08849 & 2293.239 & 1153.100 & 77.44061 & 77.31806 & 0.48 \\
S28 & 40.58636 & 767.0901 & 1191.486 & 43.17296 & 44.01666 & 0.45 \\
S31 & 8.603349 & 1617.611 & 1182.830 & 50.90023 & 45.47575 & 0.65 \\
S39 & 46.08572 & 607.0457 & 1153.895 & 76.73050 & 43.42295 & 0.56 \\
S48 & 21.26112 & 0 & 1208.221 & 28.23364 & 13.07559 & 0.57 \\
S56 & 79.51032 & 2657.720 & 1179.433 & 53.93271 & 114.9219 & 0.29 \\
\hline
\end{tabular}

We see the behavior of the total required budget and all supermarkets' efficiency in Figure 1. we observe various behaviors of different supermarkets that show no unique pattern for all supermarkets. Thus, we investigate different budgeting plans for individual supermarkets; we report it for one efficient and one inefficient supermarket.

Considering a given gradual level of income, we look for required input levels that are capable of gaining aforesaid income level. Consider supermarket \#1 (S1) for this analysis; for instance, that is an inefficient supermarket using its resources to produce its outputs. Let us consider the different amounts of income are considered, and required input levels are found for gaining those income levels, using model (3.3). Table 3 reports the result of this analysis. It assumes a gradual expecting income from 50 to 700 million Rial income. To reach 50 million Rial income in this supermarket, we do not need to much resources, not the extra size or man-hour in this case. Recall that supermarket is inefficient there exist possible performance improvement for 


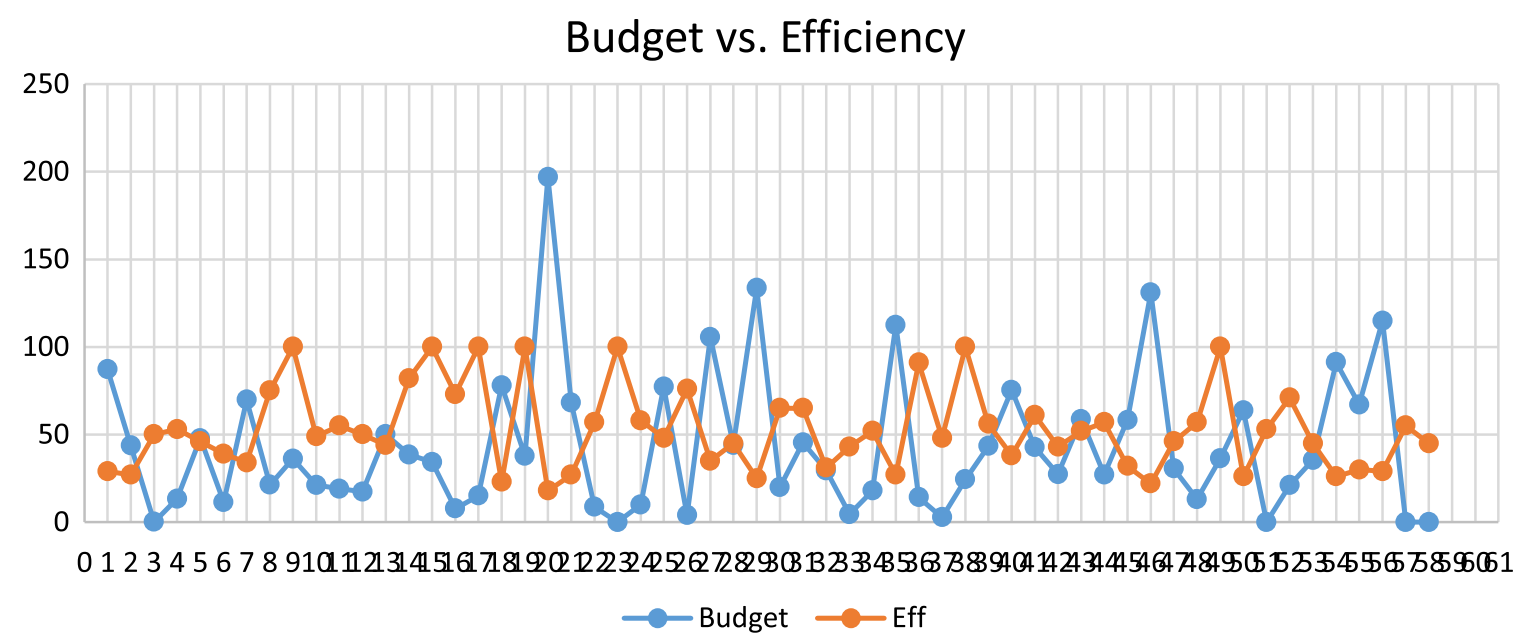

FIGURE 1. The required input vs. efficiency of all supermarkets.

TABLE 3. Gradual income analysis for S1.

\begin{tabular}{llllll}
\hline \hline Expected income & $\Delta x_{1}$ & $\Delta x_{2}$ & $\Delta y_{1}$ & $\Delta y_{2}$ & Required resources \\
\hline 50 & 0.0041 & 0 & 309.9622 & 0 & 0.00256 \\
100 & 20.92555 & 384.0339 & 603.8656 & 14.33561 & 22.40938 \\
200 & 65.69445 & 1888.967 & 1189.426 & 45.01186 & 87.32781 \\
300 & 110.4633 & 3393.900 & 1774.987 & 75.68810 & 152.2462 \\
400 & 155.2322 & 4898.834 & 2360.548 & 106.3644 & 217.1646 \\
700 & 289.5389 & 9413.633 & 4117.230 & 198.3931 & 411.9199 \\
\hline
\end{tabular}

TABLE 4. Gradual income analysis for S9.

\begin{tabular}{llllll}
\hline \hline Expected income & $\Delta x_{1}$ & $\Delta x_{2}$ & $\Delta y_{1}$ & $\Delta y_{2}$ & Required resources \\
\hline 50 & 0 & 363.9278 & 281.4231 & 25.4 & 9.040693 \\
100 & 0 & 727.8555 & 562.8462 & 50.9 & 18.08139 \\
200 & 0 & 1455.711 & 1125.692 & 101.9 & 36.16277 \\
300 & 9.0004 & 1981.535 & 1704.286 & 138.8 & 54.76060 \\
400 & 21.9834 & 2417.966 & 2289.846 & 169.4 & 73.58695 \\
700 & 60.9324 & 3727.258 & 4046.528 & 261.5 & 130.0660 \\
\hline
\end{tabular}

this supermarket. This means that more income is possible for this supermarket with its current input levels. However, increasing expected output requires more resources. In the next analysis, we consider S9 that is an efficient supermarket and perform the same analysis for this efficient supermarket. The result is reported in the Table 4. The result shows no extra size for the expanding plans up to 200 million Rial income, instead more labor is found that is require for this supermarket. Figures 2 and 3 depict the pattern of income vs. cost of these plans for S1 and S2 as an efficient and inefficient supermarket. An overview of these figure suggest an expanding income plan for S1 up to 50 million Rial at most and a income expanding plan up to 700 million Rial for S9 as an efficient supermarket. 


\section{Expected Income vs. Required budget}

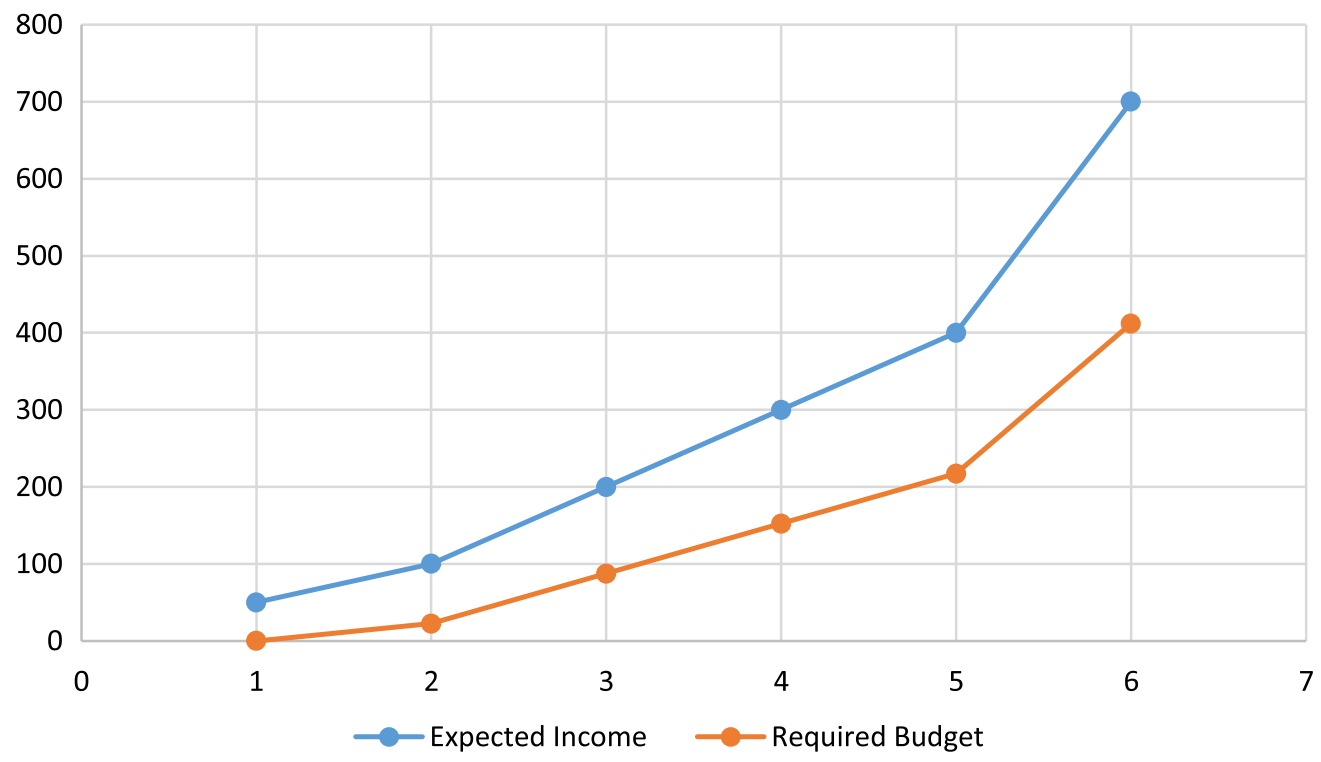

FiguRE 2. Expected income vs. required budget for S1.

\section{Expeced Income vs. Required Budget}

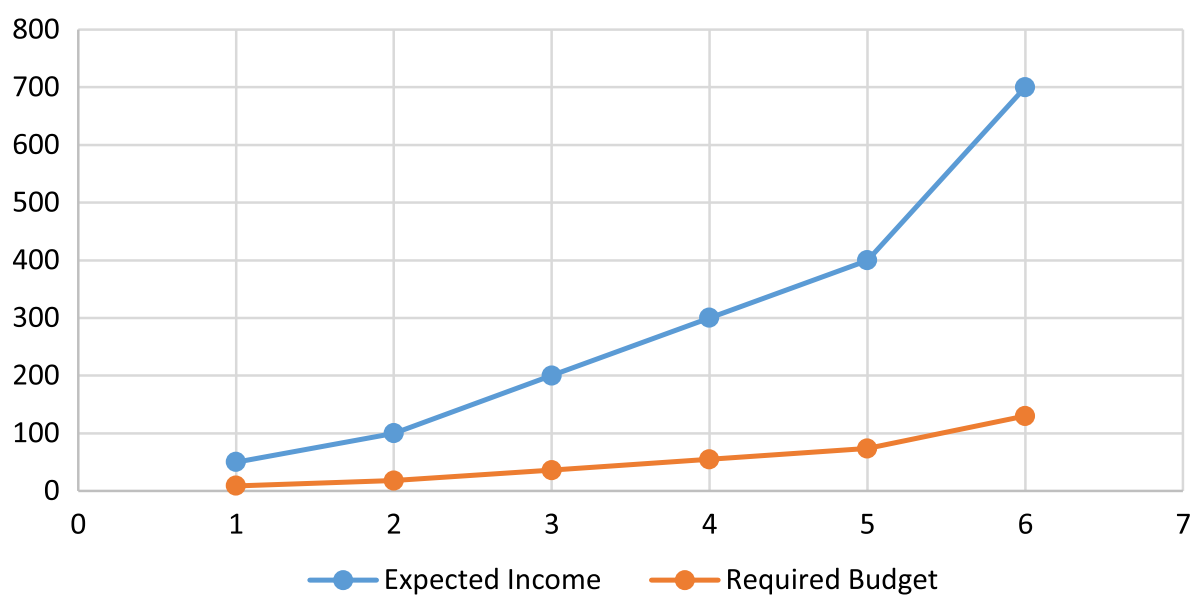

FIGURE 3. Expected income vs. required budget for S9.

In the second part of the analysis, namely, the budget-based analysis, we consider an available and equal amount of budget. Let us say 10 million Rials for each supermarket and investigate for the maximum level of income gained. Now we are interested in finding the maximum level of income that can be gain by this level of budget for each supermarket. The results are reported in Table 5. We see not only producible income in this result but also associated input share and output share for getting to this aim. 
TABLE 5. The result of the budget-based model for all supermarkets.

\begin{tabular}{lllllll}
\hline \hline Supermarket & $\Delta x_{1}$ & $\Delta x_{2}$ & $\Delta y_{1}$ & $\Delta y_{2}$ & Gained income & Output efficiency score $\varphi_{j}$ \\
\hline S1 & 12.36782 & 96.36060 & 491.4426 & 8.4 & 80.80080 & 3.45 \\
S2 & 16.26016 & 0 & 678.8406 & 10.35503 & 111.3749 & 3.72 \\
S10 & 16.26016 & 0 & 806.4409 & 19.16507 & 133.5501 & 2.02 \\
S18 & 16.26016 & 0 & 472.6951 & 17.92240 & 79.48903 & 3.37 \\
S25 & 0 & 402.5441 & 149.0833 & 13.80490 & 26.54317 & 2.08 \\
S28 & 16.26016 & 0 & 699.3157 & 17.38922 & 115.9489 & 2.22 \\
S31 & 0 & 402.5441 & 463.6542 & 0 & 74.79206 & 1.53 \\
S39 & 16.26016 & 0 & 412.6616 & 37.89890 & 73.41477 & 1.77 \\
S48 & 16.26016 & 0 & 1094.253 & 22.26312 & 180.5370 & 1.74 \\
S56 & 7.154292 & 225.4291 & 243.9881 & 4.926790 & 40.24800 & 3.42 \\
\hline
\end{tabular}

TABLE 6. Different budget setting and producible income for S1.

\begin{tabular}{llllll}
\hline \hline Available budget & $\Delta x_{1}$ & $\Delta x_{2}$ & $\Delta y_{1}$ & $\Delta y_{2}$ & Gained income \\
\hline 5 & 8.130081 & 0 & 436.0422 & 5.5 & 71.33971 \\
10 & 12.36782 & 96.36060 & 491.4426 & 8.4 & 80.80080 \\
20 & 19.26400 & 328.1797 & 581.5970 & 13.1 & 96.19705 \\
50 & 39.95253 & 1023.637 & 852.0602 & 27.3 & 142.3858 \\
\hline
\end{tabular}

TABLE 7. Different budget setting and producible income for S9.

\begin{tabular}{llllll}
\hline \hline Available budget & $\Delta x_{1}$ & $\Delta x_{2}$ & $\Delta y_{1}$ & $\Delta y_{2}$ & Gained income \\
\hline 5 & 0 & 201.2720 & 155.6424 & 14 & 27.65275 \\
10 & 0 & 402.5441 & 311.2849 & 28.1 & 55.30549 \\
20 & 0 & 805.0882 & 622.5697 & 56.3 & 110.6110 \\
50 & 5.717492 & 1871.176 & 1556.215 & 131.0 & 274.7131 \\
\hline
\end{tabular}

Like the previous run, we observe different behavior from various supermarkets. However, most supermarkets' main observation is expanding the available for size expansion rather than hiring more labor. In fact, $60 \%$ of supermarkets prefer the aforementioned pattern.

Now we go one step forward and investigate the effect of the different available budgets for individual supermarkets and report this for one efficient and one inefficient supermarket. Take S1 into consideration that it is an inefficient supermarket. The budget-based model for this supermarket for having different budget levels is reported in Table 6. It is considering 5 million Rial extra budget yields to almost 71 million Rial more income, in total. This requires almost 8 percentages more size, and no more labor is needed in this case. We perform this analysis for an efficient supermarket, too, that is S9. The result is reported in Table 7. In contrast with S1, no extra size is required, and instead, more labor is needed in different budget levels for S9.

Figures 4 and 5 depict the result of the budget-based method for S1 and S9. As can be seen.

While the available budget and gained income increase with almost the same pattern, we observe a high potential of income gaining by more budget, specifically when we increase the budget level from 3 million Rial to 4 million Rial. In this case, when we increase the budget level by just one percent, we observe more than 2.5 income increments. Such information is vital for decision-makers when budgeting and future planning in the retailer sectors, including supermarkets. Such an analysis can be performed for all supermarkets separately, and 


\section{Budget vs. Income for S1}

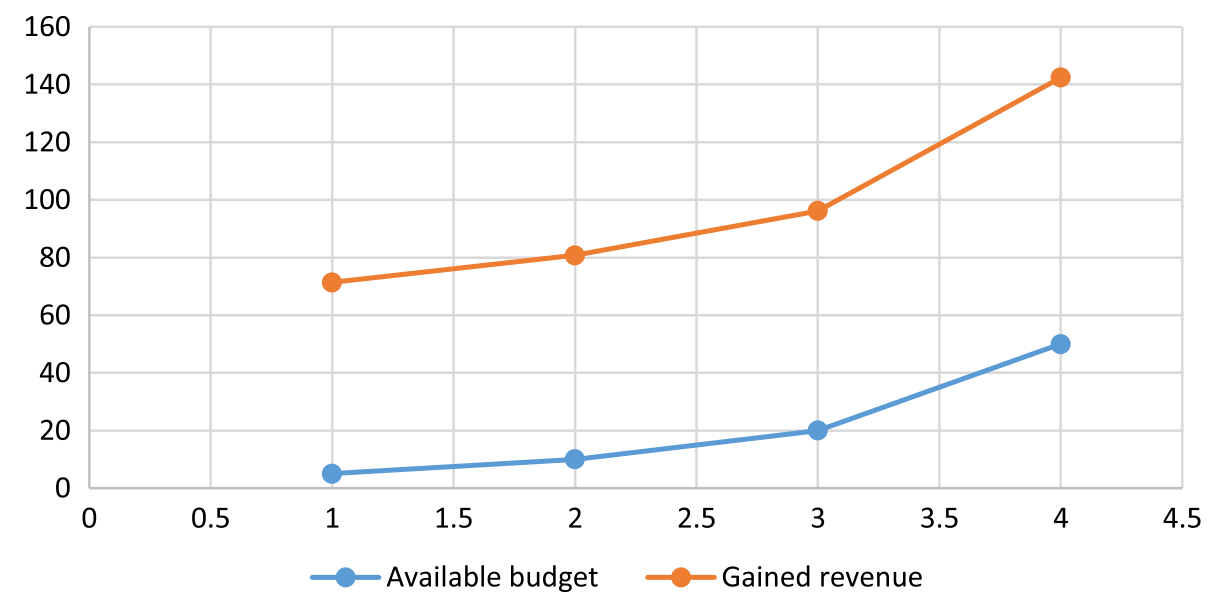

Figure 4. Available budget vs. gain income based of income model for S1.

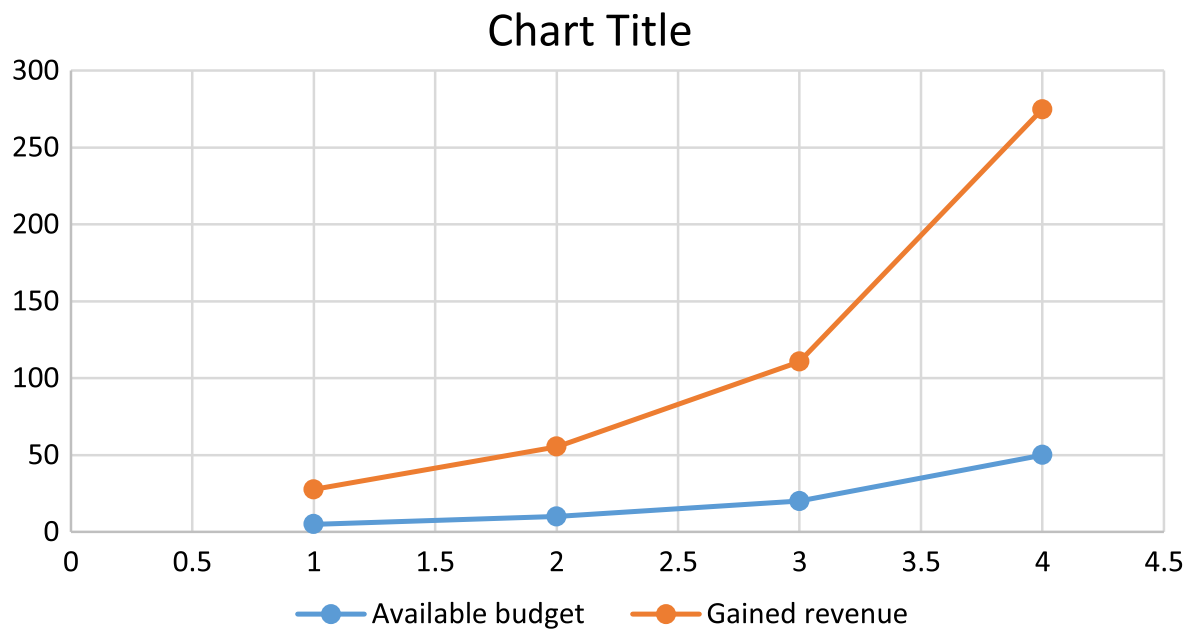

Figure 5. Available budget vs. gain income based of income model for S9.

the decision-maker's preferences and policies can set more proposed models on budgeting and future planning. In any production system, we face budgeting or planning regarding the limitation of resources. On the other hand, price availability provides the possibility of more deep analysis to get more insight from the production process. Thus, propose models help decision-makers in the procedure of input-output analysis taking the budgeting or planning (each one that is required) into account. Therefore, proposed models can be used for begetting and planning procedures of not only the business sectors but also for any business and production system while taking the efficiency status into consideration. 


\section{CONCLUSiOn}

There has always been an interesting and important question for DMs that how to invest the budget within different segments. On the other side, estimating required input and producible output are also vital issues in future planning. This paper proposes two inverse DEA-based models to assist DMs on the budgeting and planning issue. This yields to a new class of inverse DEA problem that their strength and applicability is shown in a real-life problem. In any input-output analysis in real-world problems, we can use proposed models in the current paper when price information is available. Proposed models are general and can be used in any production system that is concerned about the budgeting and planning in the process of input-output estimation.

\section{REFERENCES}

[1] G.R. Amin and M.I. Boamah, A new inverse DEA cost efficiency model for estimating potential merger gains: a case of Canadian banks. Ann. Oper. Res. 295 (2020) 21-36.

[2] G.R. Amin and A. Emrouznejad, Inverse forecasting: a new approach for predictive modeling. Comput. Ind. Eng. 53 (2007) 491-498.

[3] G.R. Amin, A. Emrouznejad and S. Gattoufi, Minor and major consolidations in inverse DEA: Definition and determination. Comput. Ind. Eng. 103 (2017) 193-200.

[4] A. Charnes, W.W. Cooper and E. Rhodes, Measuring the efficiency of decision making units. Eur. J. Oper. Res. 2 (1978) $429-444$.

[5] L. Chen, Y. Wang, F. Lai, and F. Feng, An investment analysis for China's sustainable development based on inverse data envelopment analysis. J. Clean. Prod. 142 (2017) 1638-1649.

[6] W.D. Cook and L.M. Seiford, Data envelopment analysis (DEA) - Thirty years on. Eur. J. Oper. Res. 192 (2009) 1-17.

[7] A. Emrouznejad, G.-L. Yang and G.R. Amin, A novel inverse DEA model with application to allocate the $\mathrm{CO}_{2}$ emissions quota to different regions in Chinese manufacturing industries. J. Oper. Res. Soc. (2018) 1-12.

[8] S. Gattoufi, G.R. Amin and A. Emrouznejad, A new inverse DEA method for merging banks. IMA J. Manage. Math. 25 (2014) 73-87.

[9] M. Ghiyasi, Industrial sector environmental planning and energy efficiency of Iranian provinces. J. Cleaner Prod. 142 (2017) 2328-2339.

[10] M. Ghiyasi, Inverse DEA based on cost and revenue efficiency. Comput. Ind. Eng. 114 (2017) 258-263.

[11] S. Ghobadi and S. Jahangiri, Inverse DEA: review, extension and application. Int. J. Inf. Technol. Decis. Making 14 (2015) 805-824.

[12] F. Guijarro, M. Martínez-Gómez and D. Visbal-Cadavid, A model for sector restructuring through genetic algorithm and inverse DEA. Expert Syst. App. 154 (2020) 113422.

[13] A. Hadi-Vencheh and A.A. Foroughi, A generalized DEA model for inputs/outputs estimation. Math. Comput. Modell. 43 (2006) 447-457.

[14] A. Hadi-Vencheh, A.A. Foroughi and M. Soleimani-Damaneh, A DEA model for resource allocation. Econ. Modell. 25 (2008) 983-993.

[15] A. Hatami-Marbini, A. Emrouznejad and M. Tavana, A taxonomy and review of the fuzzy data envelopment analysis literature: two decades in the making. Eur. J. Oper. Res. 214 (2011) 457-472.

[16] G.R. Jahanshahloo, F.H. Lotfi, N. Shoja, G. Tohidi and S. Razavyan, Input estimation and identification of extra inputs in inverse DEA models. Appl. Math. Comput. 156 (2004) 427-437.

[17] G.R. Jahanshahloo, A.H. Vencheh, A.A. Foroughi and R.K. Matin, Inputs/outputs estimation in DEA when some factors are undesirable. Appl. Math. Comput. 156 (2004) 19-32.

[18] G.R. Jahanshahloo, F.H. Lotfi, N. Shoja, G. Tohidi and S. Razavyan, Sensitivity of efficiency classifications in the inverse DEA models. Appl. Mat. Comput. 169 (2005) 905-916.

[19] G. Jahanshahloo, F. Hosseinzadeh Lotfi, M. Rostamy-Malkhalifeh and S. Ghobadi, Using enhanced Russell model to solve inverse data envelopment analysis problems. Sci. World J. (2014) 2014.

[20] G.R. Jahanshahloo, M. Soleimani-Damaneh and S. Ghobadi, Inverse DEA under inter-temporal dependence using multipleobjective programming. Eur. J. Oper. Res. 240 (2015) 447-456.

[21] M. Kalantary, R. F. Saen, and A. Toloie Eshlaghy, Sustainability assessment of supply chains by inverse network dynamic data envelopment analysis. Sci. Iran. 25 (2018) 3723-3743.

[22] M. Kalantary, and R. F. Saen, Assessing sustainability of supply chains: An inverse network dynamic DEA model. Comput. Ind. Eng. 135 (2018) 1224-1238.

[23] S. Lertworasirikul, P. Charnsethikul and S.-C. Fang, Inverse data envelopment analysis model to preserve relative efficiency values: the case of variable returns to scale. Comput. Ind. Eng. 61 (2011) 1017-1023.

[24] H.-T. Lin, An efficiency-driven approach for setting revenue target. Decis. Support Syst. 49 (2010) 311-317.

[25] Q. Wei, J. Zhang and X. Zhang, An inverse DEA model for inputs/outputs estimate. Eur. J. Oper. Res. 121 (2000) $151-163$. 
[26] H. Yan, Q. Wei and G. Hao, DEA models for resource reallocation and production input/output estimation. Eur. J. Oper. Res. 136 (2002) 19-31.

[27] G. Zhang and J. Cui, A general inverse DEA model for non-radial DEA. Comput. Ind. Eng. 142 (2020) 106368. 